\title{
ANALYSIS OF SUSTAINABLE HEALTH POLICY DEVELOPMENT IN HOSPITAL ON LOMBOK ISLAND: APPLICATION OF QCA METHODS
}

\author{
Sri Sulistiowati* \\ Postgraduate Program of Doctoral Economics, University of Udayana, Denpasar, \\ Bali, Indonesia \\ Wiwin Setyari Putu, Nyoman Saskara Ida Ayu \\ Department of Development Economic, Faculty of Economics and Business, \\ University of Udayana, Denpasar, Bali, Indonesia \\ *E-mail: srisulistiowati2020@gmail.com
}

\begin{abstract}
This study aims to determine the factors that determine the formation of a synergy of conditions that are indispensable in the development of optimal sustainable health policies in hospitals on the island of Lombok. This study uses a prospective analysis approach to explain the current situation complemented by thoughts that reach into the future. Data collection was carried out by means of interviews, questionnaires and focus group discussions. Indicator of condition synergy uses good hospital governance parameters from KARS and WHO. Data analysis using Qualitative Comparative Analysis (QCA) method assisted with Tosmana software. The results showed that all the main stakeholder actors in the hospitals on Lombok Island supported the establishment of an optimal sustainable health policy. The governance factors that strongly support the realization of an optimal sustainable health policy are the number of Doctors. While other factors that need to be strengthened to establish an optimal sustainable health policy are the Budget, Beds, and Medical Personnel.
\end{abstract}

\section{KEY WORDS}

Hospital, health, policy, qualitative comparative analysis (QCA).

As the population grows, the need for health services is increasing. The existence of a hospital is very important to provide health services for the community. Based on data from the Ministry of Health, the number of hospitals in NTB Province was 36 units until the end of 2018. The number is still far behind that of other provinces in Indonesia. Likewise, the ratio of hospital beds per 1,000 population, where NTB is the province with the lowest ratio. Some of these data and facts are the basis for further research related to health policy in the NTB Province in general, and in Lombok Island in particular. In this study more focused on health services on the island of Lombok, the reason is because the majority of the population in the province of NTB is concentrated on the island of Lombok. In addition, the number of private hospitals operating in Lombok Island will have an impact on the health policies that apply to the region, where hospitals owned by regency / city governments (RSUD) are required to be more competitive in competition with private hospitals.

There are 4 District Government Hospitals and 1 City Government Hospital. Overall, all of these hospitals have been accredited with a grade of $C$, only Mataram City Hospital that received an accreditation $B$. The distribution of existing health resources around the hospital does not guarantee that the performance of the RSUD will always be high and the quality of the health services provided will increase. The budget surplus that occurs at RSUD also does not necessarily improve the quality of health services. In addition, the high budget also cannot guarantee better quality of health service delivery to the community. When viewed from the budget, it is generally known that all hospitals have a budget surplus between the target and the realization. The facts in the field show that the number of dead patients in all hospitals is increasing every year. If averaged, there was an increase in the number of dead patients by 13.83 percent annually during the $2014-2017$ period. When the budget should 
increase, the number of dead patients can be reduced to a lower level because the distribution of health services provided to the public is of better quality.

If seen from the ratio between cured and dead patients, the figure tends to be stable at 4 percent every year for all hospitals. Of course, this figure can be stated relatively well, but when viewed in absolute terms the death rate of patients is getting higher which indicates that hospitals are not able to provide the best health services. Of course this affects the assessment of the community as service recipients negatively towards the RSUD. Moreover, from the point of view of the government as the policy maker, RSUD also received a negative rating because it was declared unable to use the budget effectively and efficiently. Meanwhile on the part of RSUD, the high mortality rate of patients became their main obstacle in the effort to gain public trust related to improving public health services.

The lack of priorities and the integration of the use of the budget for the completeness of medical equipment with the use of the budget in an effort to improve public health services is a major problem in the development of public health on the island of Lombok. This can have implications for the low success rate of hospitals in delivering health services. Therefore, for the development of public health on the island of Lombok to be successful it requires the selection of priorities and strategies that can integrate the use of the budget for the needs of medical services with the quality status of integrated medical services.

Effective health policies and the allocation of public health resources can substantially improve public health (Brownson, Seiler \& Eyler, 2010). In a study conducted by Brownson et.al., it was found that there was a set of consensus metrics that could be developed for evaluating health policy performance. This metric can be used to identify factors that can help improve effective health policies.

Community development can be reflected in the quality of the health of its population, how much health is distributed at all social levels, and the effectiveness of health risk protection provided by public policy (WHO, 2008). Determinants of the level of public health in general are related to the socio-economic and political contexts such as government, social and public policy (Thammatach-aree, 2011). The problem of inequality in health arises as a result of uneven distribution of health resources in each region, which creates or limits the ability of underprivileged families to obtain health services and healthy livelihoods.

From the explanation of several phenomena that become the main problems in implementing health policies, it turns out that the government still faces many problems which certainly have an impact on the performance of hospitals as implementing public health service activities. Related to the problems that have been described, it is necessary to conduct an in-depth study by emphasizing the implementation of hospital health policies in realizing social welfare related to health services. The strategies implemented by each hospital need to be reviewed, so that later an effective-efficient implementation model can be built in accordance with a sustainable health policy that aims to provide excellent health services to the community. Referring to the background thinking and scope of the research described, a research problem was formulated, namely: "What is the role of each variable in shaping policies to improve service quality in each district / city government hospital on the island of Lombok?

\section{LITERATURE REVIEW}

The health sector is an important part of the economy in various countries. Some opinions state that the health sector is like a sponge, absorbing a lot of national resources to fund many health workers. Other opinions suggest that the health sector such as generating economies, through innovation and investment in biomedical technology or the production and sale of medicines, or by ensuring a healthy population that is economically productive. Some community members visit health facilities as patients or customers, utilizing hospitals, clinics or pharmacies; or as a health profession, nurse, doctor, health support, pharmacist or manager. Because health decision making is related to death and safety, health is placed in a more privileged position compared to other social problems (Buse et al., 2005).

Theoretically, the health policy strategy is a public policy to gather all potentials to 
maintain and improve the public health status (Detels, et al., 2002), and according to Downie (2000) these efforts need to involve all community forces. Collins (2005) also stated that in policy analysis there are two areas, namely analysis of the policy process and analysis of policy content. In this analysis the focus is more on the contents of the policy itself, specifically the policy on hospital reform, and compliance with the implementers in the regions implementing health policies from the Central Government.

The health system is needed in health development, this health system will work to increase life expectancy, reduce the burden of disease and increase attitudes and behavior, as well as fulfillment of people's satisfaction with health services. As stated in the Strategic Review of Health and Medical Research, this health system consists of resources, unit costs of people (health personnel costs and health facility costs), productivity (clinical services per person), and effectiveness (health outcomes per clinical service) (McKeon, 2013).

In Indonesia, the debate on health development is too dependent on arguments about increasing resources, and it is not enough just to increase productivity and effectiveness through microeconomic reform and the application of innovation from research. The total resources available and the cost of the people is determined by the allocation of the government budget. On the other hand, productivity and effectiveness are driven by choices of interventions that have diverse costs and impacts on health outcomes. Decisions about some of these interventions, such as vaccinations, are made at the population level as a public health policy, while others are choices made by health professionals in hospitals and other settings.

\section{METHODS OF RESEARCH}

This research is a analytical descriptive method mix method using a method called Qualitative Comparative Analysis (QCA). As a descriptive-analytical study, the research will explain the dynamics of the implementation of the accreditation status of medical services and the budget increase policy at each district / city government hospital on the island of Lombok by observing the development and implementation of the budget accreditation and policies in the regions. QCA is used because this study is included in the scope of small cases with the aim of collecting depth understanding and capturing dimensions of complexity of cases while still allowing generalizations to occur. QCA enables synthetic strategy as a middle ground that facilitates the case-oriented and variable-oriented nature of research. As a case-sensitive approach, QCA allows a separate form of causality, namely as causality called multiple conjuctural causation (Rihoux et.al., 2011).

\section{RESULTS OF STUDY}

The context of domestic structure basically can be seen and illustrated to explain the factors that influence the existence of normative reasons for health policies that apply to each district / city area on the island of Lombok. Data processing in this study using the QCA software results obtained in the form of a Truth Table as presented in Table 1. The QCA output presented in Table 1 shows the level of contribution of each stakeholder actor in supporting the realization of optimal sustainable health policy in hospitals on Lombok Island. From this table it is known that all major stakeholder actors support the realization of institutional synergy with different levels of contributions. The level of contribution is measured through 4 (four) parameters / factors of good governance. The level of contribution of each actor varies according to perceptions, availability of resources, authority and governance capabilities of hospitals that are owned.

Table 1 - QCA Truth Table Analysis of Sustainable Health Policies

\begin{tabular}{|c|c|c|c|c|c|}
\hline ID & ANGGARAN & TT & DOKTER & MEDIS & KESEMBUHAN PASIEN \\
\hline RSPraya, RSGerung & 0 & 0 & 0 & 0 & 1 \\
\hline RSSelong(0), RSMataram(1) & 0 & 0 & 1 & 0 & C \\
\hline
\end{tabular}


The results of the Truth Table Analysis show that there are 2 regional clusters based on the interaction of conditions and outcomes, namely Praya Hospital and Gerung Hospital, and contradictory cluster namely Selong Hospital and Mataram Hospital. Visually, the cluster can be seen in Venn diagrams generated from the Tosmana software. Based on typological development that has been done, the findings on the four variables above produce a typological QCA building chart as follows:

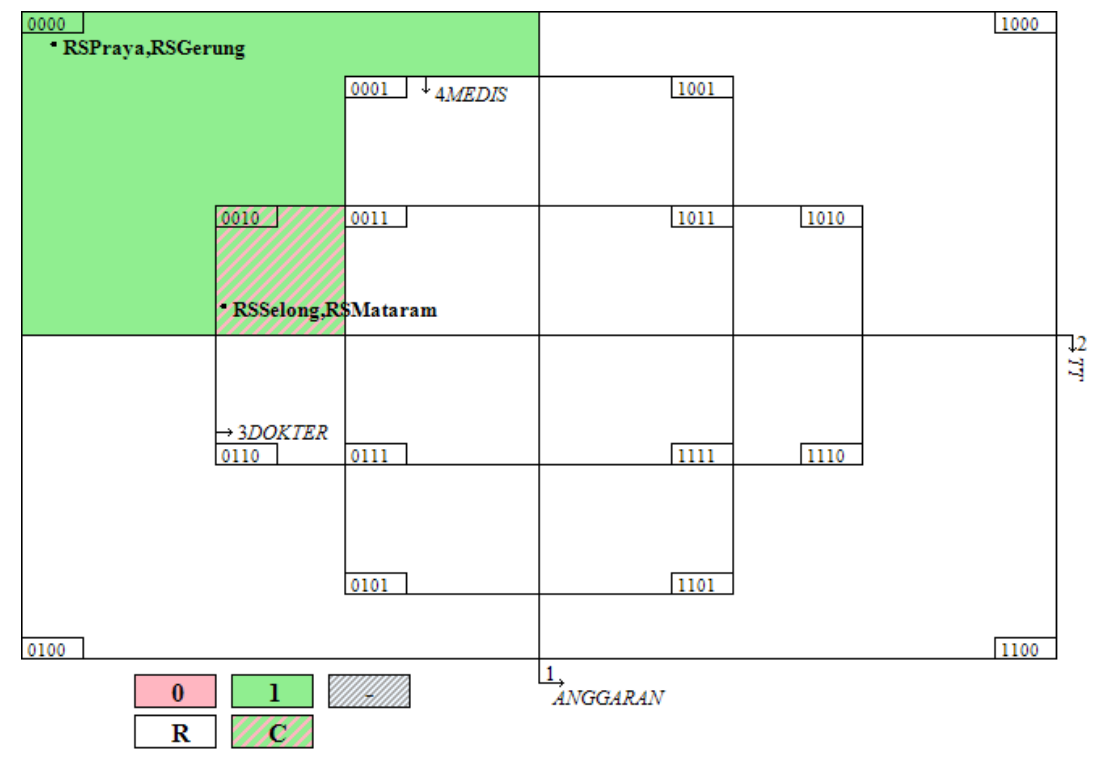

The Venn diagram for the two conditions like in the picture above divides the twodimensional plane into four quadrants and the area in the middle is the intersection area between conditions. The vertical center line divides the Budget conditions into two sides. On the left shows Anggara with a value of 0 (absent), while on the right with a value of 1 (absent). The horizontal center line divides the condition of the Bed (TT) into two parts, the lower part represents the value of TT $=1$, while the upper part represents the value of TT = 0 . The box in the middle of the Venn diagram illustrates the third condition ie Doctor, the area inside the middle box represents the value Doctor $=1$, while the area outside the middle box illustrates the value of Doctor $=0$. Furthermore, the deepest box represents the fourth condition, which is Medical, the area inside the box represents Medical value $=1$, while the area outside the box represents the Medical value $=0$. Legend in Below the Venn diagram shows the output where the value 0 represents no outcome, the value 1 indicates that there is an outcome. While the value of $\mathrm{C}$ shows contradictory outcomes and $\mathrm{R}$ indicates Remainder outcomes, which means that empirically is not supported by existing data, but in theory it is possible.

In this chart, it can be seen that positive outcomes where optimal conditions are achieved can be found in the case of Praya Hospital and Gerung Hospital with each combination of factors that accompany it. In the case of positive outcomes, it is known that with the realized budget conditions always below the target, the limited number of hospitals available, the limited number of doctors, and the limited number of medical staff have also been able to create conditions that support the achievement of policies optimal sustainable health at RSUD.

In contradictory outcomes, that is a condition in which health policies have the same input values but differ in the outcomes produced. It is known that optimal sustainable health policy outcomes can be found in the case of Mataram Hospital with each combination of factors accompanying it, where conditions with a large number of Doctor resources, health policies can be channeled properly to the entire community. Meanwhile, with the same conditions but resulting in different outcomes occurring at Selong Hospital, it is known that the large number of Doctor resources is not able to produce a sustainable health policy in an effort to reduce mortality, as can be seen based on the typological structure above. 
To find out the factors that influence negative outcomes, the combination of positive outcomes will be compared with a combination of conditions in negative outcomes in order to get a picture of the alleged distinguishing factors that are determinants in influencing existing outcomes. By doing this, we will get a causative pattern called multiple conjuctural causation (multiple conjunctural causes). This causative pattern is not the result of a generalization of a causal pattern, but rather the result of an interpretation of the alleged (comparable) conditions which differentiate the outcome of the case.

Cases found in Selong Hospital basically have almost the same modality as the combined modality of conditions found in the positive outcomes of Mataram Hospital. In that case, basically there is an interest of the local government to arrange a doctor, but it seems that this interest is not manifested in the policies that have been taken. The differentiator in these cases (the Praya Hospital and Gerung Hospital cases) with positive outcomes lies in managing the needs of doctors as outlined by the local government in the decided health policy. While the difference between these cases with Mataram Hospital which is able to produce positive outcomes with the same conditions is the presence of a driving force in the form of social capital that has been formed.

Therefore, based on the results of the QCA analysis carried out through typological development and case interpretation, multiple conjuctural causation found on the achievement of an optimal sustainable health policy which in fact is an inhibiting factor for the distribution of health services on Lombok Island is an inappropriate health policy factor related with the needs of the Doctor. Erroneous health policy because it is not based on this data can be caused by political structures that tend to be closed so as not to open significant space for the inclusion of discourses based on public health approaches due to a lot of emphasis on local wisdom and power politics. Thus, health perceptions and health policy priorities are also important determinants in influencing an area's drive to make health policy arrangements as part of the region's social justice.

\section{CONCLUSION}

Based on the results of a qualitative comparative analysis (QCA) on the health policy structure of the RSUD on Lombok Island, the four stakeholder actors associated with the development of optimal sustainable health policy have a generally strong enough contribution, although there are differences in the level of contribution and types of factors supported among stakeholder actors, in addition there are also similarities. The governance factors that support the RSUD very strongly for the realization of optimal sustainable health policies are the Budget, Beds, Doctors and Medical.

For the development of the health policy of RSUD in Lombok Island, based on research reflection which found a high level of sensitivity in terms of regulating the number of Doctors at RSUD on Lombok Island, this study will propose a policy of regulating the number of data-based Doctors according to the needs in the field. Basically, this concept offers a functional regulation of the number of doctors in meeting the needs of physicians while still allowing for sensitive discussions to be discussed at a technical level without causing a major problem politicization. Thus, government concerns about the possibility of not delivering health services to the public can be mitigated while still meeting the functional aspects of the regulatory needs of doctors in each hospital. In a long-term projection, this approach is expected to be able to create high trust for local governments so as to enable greater steps in regulating the number of doctors and their management in order to achieve optimal sustainable health policies.

\section{REFERENCES}

1. Brownson, R.C., Seiler, R., \& Eyler, A.A., (2010). Measuring the Impact of Public Health Policy. Preventing Chronic Disease, Public Health Research, Practice, and Policy; 7(4): 1-7.

2. Buse, K., Mays, N., \& Walt, G., (2016). Making Health Policy. London: London School 
of Hygiene \& Tropical Medicine.

3. Collins, T., (2005). Health Policy Analysis: A Simple Tool For Policy Makers. Public Health; 119(1): 192-196

4. Detels, R., \& Tan, C.C., (2002). The Scope and Concerns of Public Health. New York: Oxford University Press.

5. Downie, R.S., Fyfe, C., \& Tannahill, A., (2000). Health Promotion: Models and Values. New York: Oxford University Press.

6. Fauzi, A., 2019. Teknik Analisis Keberlanjutan. Jakarta: Gramedia Pustaka Utama.

7. McKeon, S., (2013). Strategic Review of Health and Medical Research. Canberra: Commonwealth.

8. Rihoux, B., Rezsohazy, I., \& Bol, D., (2011). Qualitative Comparative Analysis (QCA) in Public Policy Analysis: an Extensive Review. German Policy Studies; 7(3): 9-82.

9. Thammatach-aree, J., (2011). Health Systems, Public Health Programs, and Social Determinants of Health. World Conference on Social Determinants of Health.

10. WHO, (2008). Health in Asia and the Pacific. World Health Organization, South-East Asia Region, Western Pacific Region. 